Oral Section

\title{
Hormetic effect of amyloid-beta peptide in hippocampal synaptic plasticity and memory
}

\author{
Daniela Puzzo, Agostino Palmeri \\ Dept. Bio-Medical Sciences - Section of Physiology, University of Catania, Italy
}

\begin{abstract}
Background: The term hormesis refers to a biphasic dose-response phenomenon characterized by low-dose stimulation and high-dose inhibition represented by a J-shaped or U-shaped curve, depending on the parameter measured (Calabrese and Baldwin, Hum Exp Toxicol, 2002). Indeed, several, if not all, physiological molecules (i.e. glutamate, glucocorticoids, nitric oxide) are likely to present a hormetic effect, exhibiting opposite effects at high or low concentrations. In the last few years, we have focused on amyloidbeta $(\mathrm{A} \beta)$, a peptide widely known because it is produced in high amounts during Alzheimer's disease (AD). A $\beta$ is considered a toxic fragment causing synaptic dysfunction and memory impairment (Selkoe, Science, 2002). However, the peptide is normally produced in the healthy brain and growing evidences indicate that it might have a physiologic function. Aim: Based on previous results showing that picomolar concentrations of $A \beta 42$ enhance synaptic plasticity and memory (Puzzo et al, J Neurosci, 2008) and that endogenous A $\beta$ is necessary for synaptic plasticity and memory (Puzzo et al, Ann Neurol, 2011), the aim of our study was to demonstrate the hormetic role of $A \beta$ in synaptic plasticity and memory. Methods: We used 3-month old wild type mice to analyze how synaptic plasticity, measured on hippocampal slices in vitro, and spatial reference memory were modified by treatment with different doses of $\mathrm{A} \beta$ (from $2 \mathrm{pM}$ to $20 \mu \mathrm{M}$ ). Results: We demonstrated that $\mathrm{A} \beta$ has a hormetic effect (Puzzo et al, Neurobiol Aging, 2012) with low-doses (200 pM) stimulating synaptic plasticity and memory and high-doses $(\geq 200 \mathrm{nM})$ inhibiting these processes. Conclusions: Our results suggest that, paradoxically, very low doses of $A \beta$ might serve to enhance memory at appropriate concentrations and conditions. These findings raise several issues when designing effective and safe approaches to $\mathrm{AD}$ therapy.
\end{abstract}

Keywords: hormesis, peptide, hippocampus.

\section{(cc) BY-NC-ND Licensed to GIRI}

Support: this study has been funded by Alzheimer's Association Grant IIRG-09-134220 (DP).

Conflict of interest: D.P. discloses a patent, "Methods and composition for enhancing memory" $(12 / 414,160)$.

Received: 01 June 2012; Revised: 08 August 2012; Published: 30 September 2012.

Correspondence author: Daniela Puzzo, danypuzzo@yahoo.it

How to cite this article: Puzzo D, Palmeri A. Hormetic effect of amyloid-beta peptide in hippocampal synaptic plasticity and memory. Int J High Dilution Res [online]. 2012 [cited YYYY Month dd]; 11(40):156-156. Proceedings of the XXVI GIRI Symposium; 2012 Sep 20-22; Florence (Italy). GIRI; 2012; Available from: http://www.feg.unesp.br/ ojs/index.php/ijhdr/article/view/604/576 